\title{
Charge Photogeneration and Recombination in Fluorine-Substituted Polymer Solar Cells
}

\author{
Rong $\mathrm{Hu}^{1 *}$, Yurong Liu ${ }^{1}$, Jun Peng ${ }^{2}$, Jianjun Jiang ${ }^{2}$, Mengyao $\mathrm{Qing}^{2}$, Xiaochuan $\mathrm{He}^{3}$, \\ Ming-Ming $\mathrm{Huo}^{4}$ and Wei Zhang ${ }^{2,5,6 *}$
}

${ }^{1}$ School of Materials Science and Engineering, Chongqing University of Arts and Sciences, Chongqing, China, ${ }^{2}$ School of Physics and Materials Science, Guangzhou University, Guangzhou, China, ${ }^{3}$ Songshan Lake Materials Laboratory, Dongguan, China, ${ }^{4}$ Qingdao Branch, Naval Aeronautical University, Qingdao, China, ${ }^{5}$ Research Center for Advanced Information Materials (CAIM), Huangpu Research and Graduate School of Guangzhou University, Guangzhou, China, ${ }^{6}$ Guangzhou University-Linköping University Research Center on Urban Sustainable Development, Guangzhou University, Guangzhou, China

\section{OPEN ACCESS}

Edited by:

Sotiris Sotiropoulos, Aristotle University of Thessaloniki,

Greece

Reviewed by:

Jodi Szarko,

Ipomic, Germany

Jiangang Liu,

Northwestern Polytechnical

University, China

${ }^{*}$ Correspondence:

Rong $\mathrm{Hu}$

hurong_82@cqwu.edu.cn

Wei Zhang

wzhang@gzhu.edu.cn

Specialty section: This article was submitted to Physical Chemistry and Chemical Physics,

a section of the journal Frontiers in Chemistry

Received: 31 December 2021

Accepted: 31 January 2022

Published: 24 February 2022

Citation: Hu R, Liu Y, Peng J, Jiang J, Qing M, He X, Huo M-M and Zhang W (2022)

Charge Photogeneration and Recombination in Fluorine-Substituted

Polymer Solar Cells.

Front. Chem. 10:846898.

doi: $10.3389 /$ fchem.2022.846898
In this contribution, we studied the effect of fluorine substitution on photogenerated charge generation, transport, and recombination in polymer solar cells. Two conjugated polymer materials, PBDTTT-E (fluorine free) and PTB7 (one fluorine substitution), were compared thoroughly. Meanwhile, various characterization techniques, including atomic force microscopy, steady-state spectroscopy, transient absorption spectroscopy, spectroelectrochemistry, and electrical measurements, were employed to analyse the correlation between molecular structure and device performance. The results showed that the influence of fluorine substitution on both the exciton binding energy of the polymer and the carrier recombination dynamics in the ultrafast timescale on the polymer was weak. However, we found that the fluorine substitution could enhance the exciton lifetime in neat polymer film, and it also could increase the mobility of photogenerated charge. Moreover, it was found that the SOMO energy level distribution of the donor in a PTB7:PC71BM solar cell could facilitate hole transport from the donor/acceptor interface to the inner of the donor phase, showing a better advantage than the PBDTT-E:PC71BM solar cell. Therefore, fluorine substitution played a critical role for high-efficiency polymer solar cells.

Keywords: polymer solar cells, fluorine substitution, charge transport, charge recombination, power conversion efficiency

\section{INTRODUCTION}

In the field of solar energy, polymer solar cells (PSCs) have attracted much attention owing to their flexibility, low cost, light weight, material diversification, and large-area solution processing (Kim et al., 2007; Arias et al., 2010; Lu et al., 2018). Recently, the photovoltaic systems of halogenated polymers represented by PM6 or D18 blended with non-fullerene have achieved the power conversion efficiency (PCE) of 16\%-18\% (Lin et al., 2020; Liu et al., 2020; Li C. et al., 2021), even up to $19.6 \%$ (Wang et al., 2021), showing a bright application prospect.

Fluorine (F) substitution is an important method to adjust the conformation, optical, and electrical properties of polymers (Dunitz and Taylor, 1997; Jackson et al., 2013; Zhang et al., 2014; Zhang et al., 2017; Chao et al., 2018; Dehnen et al., 2021) owing to its great electronegativity and strong electron- 
withdrawing property. Hence, it is usually adopted as a substituent to substitute $\mathrm{H}$ atom on benzene (or thiophene) rings, so as to adjust the energy levels and optical absorption of a polymer in the active layer. For example, it was found that the highest occupied molecular orbital (HOMO) energy level of polymers could be shifted down by halogen substitution (Chen H. et al., 2018; Liang et al., 2010). Besides, the substitution position and the number of fluorine elements in conjugated polymer or in non-fullerene also showed a significant impact on the coplanarity of molecules, which could further determine the morphology (such as crystallinity, domain size, phase separation scale, and network interpenetrating structure) of bulk heterojunction (Jia et al., 2019; Chen F. X. et al., 2018). As known, the photophysical processes in the PSC device, such as exciton diffusion and dissociation, charge transfer, charge generation, charge transport, charge recombination, and charge collection, are closely related to the morphology of the active layer (Clarke et al., 2009; Po et al., 2010; Zhang et al., 2012). Accordingly, fluorine substitution would play an important role in the photophysical process and, consequently, the performance of polymer solar cells. The ultrafast photoelectric conversion processes in PSCs that are based on fluorine-substituted conjugated polymers (such as PTB7-Th, PffBT4T-2OD, and PBDBT-2F) have been studied extensively by using time-resolved spectroscopy and transient photoelectric measurements ( $\mathrm{Lu}$ and $\mathrm{Yu}, 2014 ; \mathrm{Wu}$ et al., 2018; Zhang et al., 2019; Wang et al., 2020). Also, most of the contributions focused on the photoelectric conversion mechanism that F-substituted polymers matched with different acceptors (Moritomo et al., 2016; Sharma et al., 2016; Sharma et al., 2018; Matheson et al., 2019; Liu et al., 2021), or morphology regulation of F-substituted polymer-based active layers (He et al., 2014; Kniepert et al., 2015; Chen L. et al., 2018). However, the targeted research about the influence of fluorine atoms on the photoelectric conversion process is still unclear yet for fluorine-substituted polymers.

In this contribution, for targeted study of the effect of fluorine substitution on photogenerated charge generation, transport, and recombination in PSCs, we consciously employed poly(thieno(3,4-b)thiophene/benzodithiophene (PTB7) and poly(4,8-bis-substitutedbenzo(1,2-b:4,5- $\left.\mathrm{b}^{\prime}\right)$ dithiophene-2,6-diyl-alt-4-substituted-thieno(3,4b)thiophene-2,6-diyl) (PBDTTT-E) as comparative research objects. Their difference is the presence or absence of a fluorine atom substitution on the thienothiophene (TT) unit (Figure 1). Multiple characterization methods, including atomic force microscopy (AFM), steady-state spectroscopy, transient absorption spectroscopy (TAS), spectroelectrochemistry (SEC), and electrical measurements, were conducted to reveal the relationship between molecular structure and device performance. The results showed that fluorine substitution had an insignificant effect on polymer exciton binding energy and carrier recombination dynamics in the ultrafast timescale. Nevertheless, it was found that fluorine substitution could enhance the lifetime of polymer exciton, and it also could increase the mobility of photogenerated charge. Moreover, we found that the singly occupied molecular orbital (SOMO) energy level distribution of the donor in the PTB7:PC71BM solar cell could facilitate hole transport from the donor/acceptor (D/A) interface to the inner of the donor phase, showing a better advantage than the PBDTTT-E: PC71BM solar cell. Thus, the longer exciton lifetime and appropriate energy level arrangement in the PTB7:PC71BM device made the PCE higher than that of the PBDTTT-E:PC71BM device.

\section{MATERIALS AND METHODS}

\section{Fabrication of PSCs}

In this work, the photovoltaic materials, PBDTTT-E $\left(M_{\mathrm{w}}>40,000\right.$, PDI: $1.8-2.0)$, PTB7 $\left(M_{\mathrm{w}}>40,000\right.$, PDI: $\left.1.8-2.0\right)$, and $(6,6)$ phenyl-C71-butyric acid methyl ester $\left(\mathrm{PC}_{71} \mathrm{BM}\right)$, were purchased from Solarmer Material Inc. (Beijing). Their chemical structures and energy levels are shown in Figure 1. The structure of the PSC device was fabricated by using an inverted configuration, that is, indium tin oxide (ITO) substrate/zinc oxide $(\mathrm{ZnO}) /$ photoactive layer/molybdenum oxide $\left(\mathrm{MoO}_{3}\right) /$ silver $(\mathrm{Ag})$. ITO glass was cleaned with deionized water, acetone, chloroform, and isopropyl alcohol in an ultrasonic cleaner, and then, ITO glass needed to be dried in a heat oven. The $\mathrm{ZnO}$ electron transport layer was spin-coated $(3,000 \mathrm{rpm}, 30 \mathrm{~s})$ with a colloidal precursor solution (zinc acetate: 2-methoxyethanol:ethanolamine $=1 \mathrm{~g}: 10 \mathrm{ml}: 0.28 \mathrm{ml}$ ). After that, the wet $\mathrm{ZnO}$ layer was annealed on a hotplate at $200^{\circ} \mathrm{C}$ for $1 \mathrm{~h}$ in air. The active layer precursor solutions, PBDTTT-E (or PTB7): $\mathrm{PC}_{71} \mathrm{BM} \quad(10 \mathrm{mg} / \mathrm{ml}: 15 \mathrm{mg} / \mathrm{ml})$, were co-dissolved in chlorobenzene solvent on a $50^{\circ} \mathrm{C}$ hotplate at the stirring condition of $500 \mathrm{rpm}$ for $12 \mathrm{~h}$, respectively. In addition, to obtain better device performance, about 3\% (in volume) 1,8diiodooctane (DIO) was added to the active layer precursor solution $1 \mathrm{~h}$ before spin coating. Afterwards, a $30 \mu \mathrm{l}$ active layer precursor solution was spin-coated on the $\mathrm{ZnO}$ layer with a speed of $1,000 \mathrm{rpm}$ for $60 \mathrm{~s} . \mathrm{MoO}_{3}(8 \mathrm{~nm})$ and $\mathrm{Ag}$ electrode $(100 \mathrm{~nm})$ layers were sequentially evaporated on the surface of the active layer, and a shadow mask was used to obtain an effective area of the device $\left(0.075 \mathrm{~cm}^{2}\right)$ in a vacuum chamber.

\section{Morphology Characterization and the $J-V$ Test}

The morphology of PBDTTT-E:PC ${ }_{71} \mathrm{BM}$ and PTB7: $\mathrm{PC}_{71} \mathrm{BM}$ active layers was characterized by atomic force microscopy (AFM-5500, Agilent) using the tapping mode. The current density-voltage $(J-V)$ curve of the device was tested by using an electrochemical workstation (Chenhua, CHI760E) with a linear sweep voltammetry (LSV) method. A light source with an intensity of $100 \mathrm{~mW} / \mathrm{cm}^{2}$ was corrected by a standard silicon solar cell before testing. The external quantum efficiency (EQE) test of the device was conducted according to the literature ( $\mathrm{Hu}$ et al., 2021a). Space charge-limited current measurement (SCLC) of PSC devices was performed using previous methods (Shang et al., 2020). All measurements were carried out at room temperature.

\section{Steady-State Optical Absorption, Photoluminescence, and Spectroelectrochemistry Measurements}

The steady-state optical absorption of the active layer was tested on a UV-Vis-NIR spectrometer (Agilent, Cary5000). 

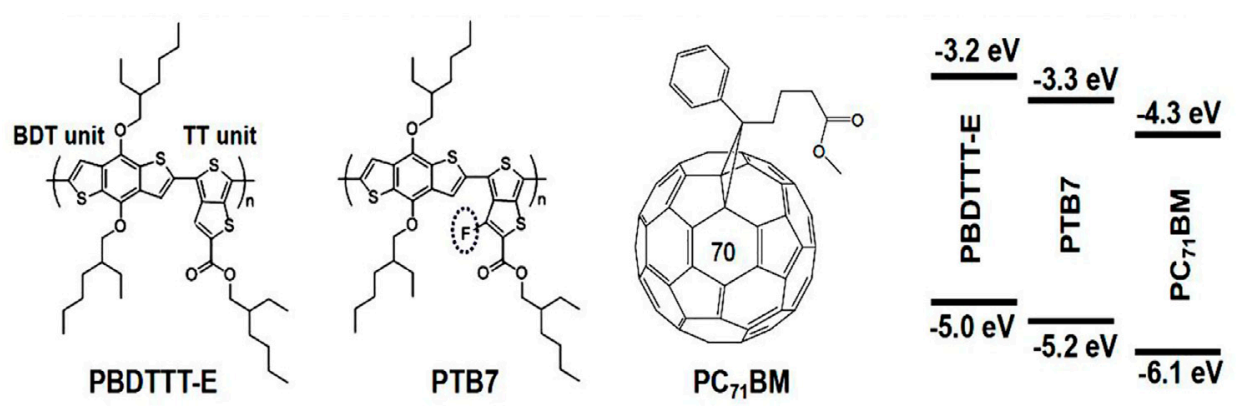

FIGURE 1 | Chemical structures of PBDTTT-E, PTB7, and $\mathrm{PC}_{71} \mathrm{BM}$ and their energy levels.

Photoluminescence measurement of the neat polymer device with the applied bias was carried out previously ( $\mathrm{Su}$ et al., 2021). The steady-state absorption spectra of polymer cations in the solution and solid state film were obtained by the SEC method. The configuration and operating condition of the SEC measurements were determined using established techniques ( $\mathrm{Hu}$ et al., 2021b; Hu et al., 2018). In this study, the oxidation potential for the solution and solid state film was applied at $1.5 \mathrm{~V}$ to obtain a polymer cation. All of the SEC spectra were obtained from the difference between absorption spectra with and without the oxidation potential. All measurements were carried out in air at room temperature.

\section{Transient Absorption Measurement}

Time-resolved absorption spectroscopy measurements were carried out by using a HARPIA-TA spectroscopy system (HARPIA, light conversion). A fs laser with a pulse width of $190 \mathrm{fs}$ and repetition rate of $100 \mathrm{kHz}(1,030 \mathrm{~nm}$, PHAROS, light conversion) was employed as the fundamental laser source of the TA system. The output of the fs laser was divided into two parts. One part was directed into an optical parametric amplifier (OPA, light conversion), and the output of OPA could be used as the pump light. The other part was used to generate probing light, that is, the white light super-continuum (WLSc). The time delay between the pump and probe was adjusted by a mechanical delay stage. All transient absorption measurements were performed at room temperature.

\section{RESULTS AND DISCUSSION}

\section{Photovoltaic Performance of Devices}

Figure 2 and Table 1 show the $J-V$, EQE characteristic curves, and photovoltaic parameters of PBDTTT-E:PC ${ }_{71} \mathrm{BM}$ and PTB7: $\mathrm{PC}_{71} \mathrm{BM}$ solar cells, respectively. As for the PBDTTT-E:PC ${ }_{71} \mathrm{BM}$ solar cell, it shows an open-circuit voltage $\left(V_{\mathrm{OC}}\right)$ of $0.632 \mathrm{~V}$, a short-circuit current density $\left(J_{\mathrm{SC}}\right)$ of $13.62 \mathrm{~mA} / \mathrm{cm}^{2}$, and a fill factor (FF) of $64.0 \%$, then achieving an average PCE of $5.51 \%$. Furthermore, these photovoltaic parameters, $V_{\mathrm{OC}}, J_{\mathrm{SC}}, \mathrm{FF}$, and PCE, are improved to $0.727 \mathrm{~V}, 15.21 \mathrm{~mA} / \mathrm{cm}^{2}, 66.6 \%$, and $7.36 \%$ in the PTB7:PC ${ }_{71} \mathrm{BM}$ solar cell, respectively. Obviously, the photoelectric conversion efficiency is enhanced due to the fluorinated TT unit. As for $V_{\mathrm{OC}}$, the PTB7-based device shows $\sim 0.1 \mathrm{~V}$ higher than that of the PBDTTT-E:PC ${ }_{71} \mathrm{BM}$ device. It is well known that $V_{\mathrm{OC}}$ of PSCs is related to the HOMO energy level of the donor and the lowest unoccupied molecular orbital (LUMO) energy level of the acceptor $\left(V_{O C}=\frac{1}{\mathrm{e}}\left(\left|E_{H O M O}^{\text {Donor }}\right|-\left|E_{L U M O}^{P C B M}\right|\right)-0.3\right)($ Dennler et al., 2008). In this study, the difference between the HOMO of PTB7 and the LUMO of $\mathrm{PC}_{71} \mathrm{BM}$ is $\sim 0.2 \mathrm{eV}$ larger than that between PBDTTT$\mathrm{E}$ and $\mathrm{PC}_{71} \mathrm{BM}$ ( $c f$. Figure 1). Thus, the higher $V_{\mathrm{OC}}$ of PTB7based device could be attributed to the lower HOMO of PTB7. To analyse the $J_{\mathrm{SC}}$ of the two devices, EQE characteristics are depicted in Figure 2B, and the PTB7:PC ${ }_{71} \mathrm{BM}$ device exhibits a greater $\mathrm{EQE}$ characteristic in the wavelength regions of 380-550 $\mathrm{nm}$ and 650-800 $\mathrm{nm}$ compared with the PBDTTT-E: $\mathrm{PC}_{71} \mathrm{BM}$ device. In the field of PSCs, EQE is usually determined by charge photogeneration and recombination processes; that is, charge photogeneration efficiency is determined by photon absorption efficiency $\left(\eta_{\mathrm{a}}\right)$, exciton diffusion and dissociation efficiency $\left(\eta_{\text {ed }}\right)$, charge transfer and transport efficiency $\left(\eta_{c t}\right)$, and charge collection efficiency $\left(\eta_{c c}\right)$, EQE $=\eta_{\mathrm{a}} \times \eta_{\text {ed }} \times \eta_{c t} \times \eta_{c c}$ (Dang et al., 2013; Lam et al., 2014). Herein, we found that PTB7:PC ${ }_{71} \mathrm{BM}$ and PBDTTT-E:PC ${ }_{71} \mathrm{BM}$ films almost had similar absorption characteristics, as shown in Figure 3. This indicates $\eta_{\mathrm{a}}$ showing the little difference in two blended films. Besides, their device configurations and fabrication processes are same, that is, $\mathrm{ITO} / \mathrm{ZnO}(30 \mathrm{~nm}) /$ active layer/ $\mathrm{MoO}_{3}(8 \mathrm{~nm}) / \mathrm{Ag}(100 \mathrm{~nm})$; thus, the $\eta_{c c}$ should be same. Therefore, the reasonable possibility is the photoelectric conversion difference $\left(\eta_{\text {ed }}\right.$ and $\left.\eta_{c t}\right)$ of two active layers to determine the EQE. FF is an important factor to evaluate the quality of polymer solar cells. Usually, it is the result of the competition between charge recombination (or loss) and charge transport. In this work, the FF of the PTB7-based device (66.6\%) was higher than that of the PBDTTT-E:PC ${ }_{71} \mathrm{BM}$ device $(64 \%)$, which could be attributed to the less charge loss in the PTB7based device.

\section{Steady-State Absorption and Photoluminescence Characteristics of Active Layers}

To analyze the effect of fluorine substitution on the absorption of active layers, the absorption features of PBDTTT-E, PTB7, 

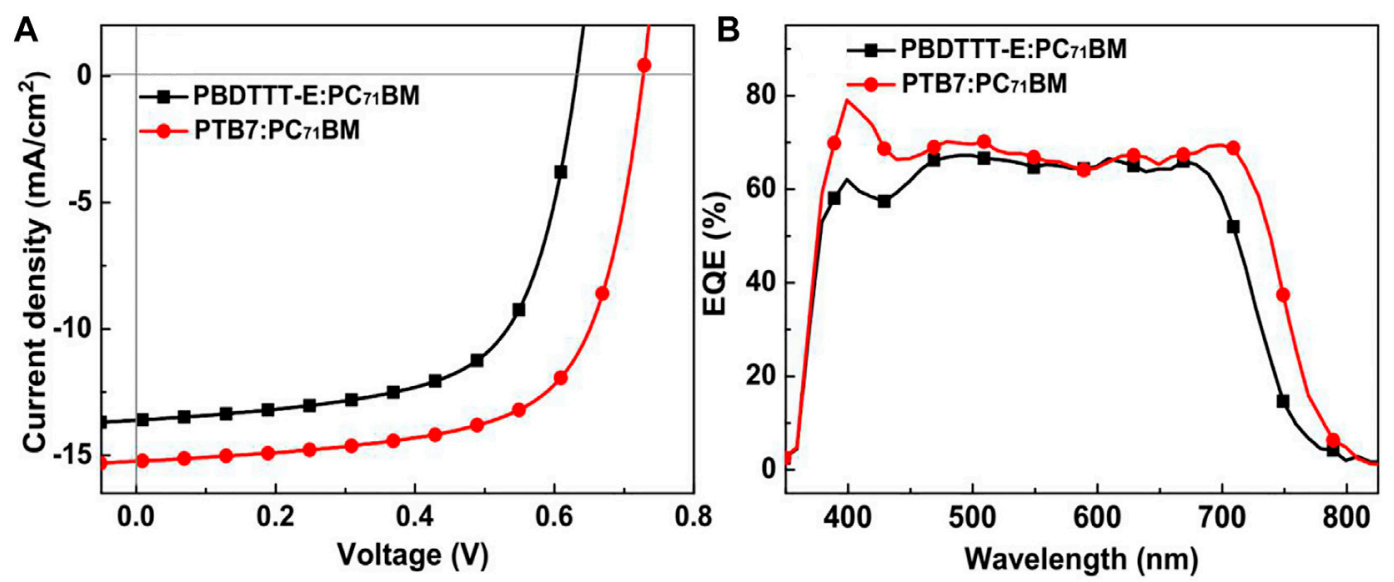

FIGURE 2 | (A) Averaged $J-V$ curves of PBDTTT-E:PC ${ }_{71}$ BM and PTB7:PC ${ }_{71} B M$ solar cells. The $J-V$ characteristics were averaged from 10 cells. (B) EQE curves of PBDTT-E:PC 71 BM and PTB7:PC 71 BM devices.

TABLE 1 | The average photovoltaic parameters of PBDTT-E:PC ${ }_{71} B M$ and $\mathrm{PTB} 7: \mathrm{PC}_{71} \mathrm{BM}$ solar cells with the corresponding deviations.

\begin{tabular}{|c|c|c|c|c|}
\hline Active layers & $v_{\mathrm{oc}}(\mathrm{V})$ & $J_{\mathrm{sc}}\left(\mathrm{mA} / \mathrm{cm}^{2}\right)$ & FF (\%) & PCE (\%) \\
\hline PBDTाT-E & $0.632 \pm 0.005$ & $13.62 \pm 0.25$ & $64.0 \pm 0.6$ & 5.51 \\
\hline PTB7:PC ${ }_{71} \mathrm{BM}$ & $0.727 \pm 0.003$ & $15.21 \pm 0.21$ & $66.6 \pm 0.7$ & 7.36 \\
\hline
\end{tabular}

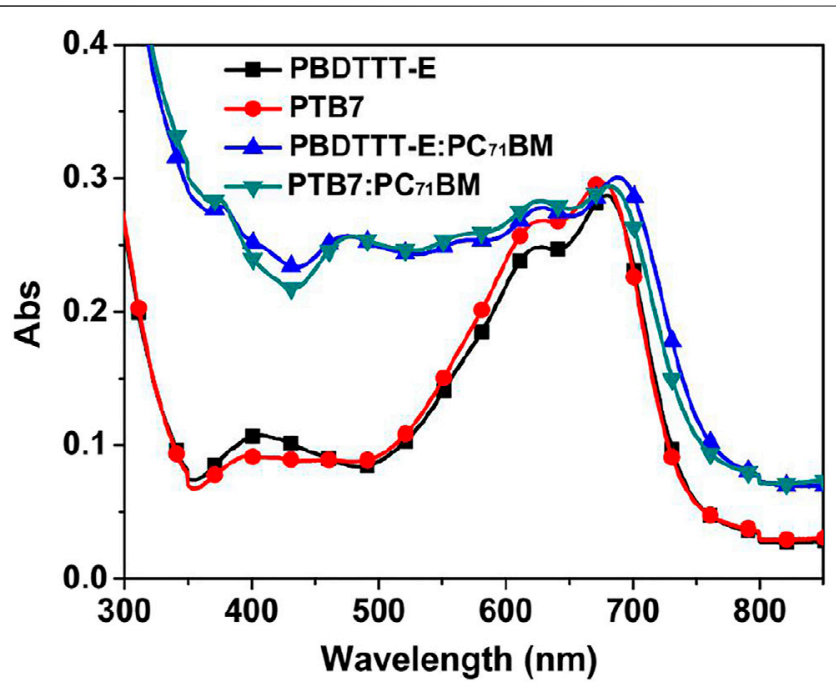

FIGURE 3 | Absorption spectra of PBDTTT-E, PTB7, PBDTTT-E: $\mathrm{PC}_{71} \mathrm{BM}$, and PTB7:PC $\mathrm{P}_{71} \mathrm{BM}$ active layers.

PBDTTT-E:PC ${ }_{71} \mathrm{BM}$, and PTB7:PC ${ }_{71} \mathrm{BM}$ active layers were tested by using a spectrometer, as shown in Figure 3. As for the neat PBDTTT-E layer, it exhibits a main absorption band in the wavelength range of $500-800 \mathrm{~nm}$ with two absorption peaks at 680 and $626 \mathrm{~nm}$. The former absorption peak is often referred to as the vibronic progression of the electronic state $\left(0^{\prime}-0\right)$, whereas the latter peak is considered as the $\left(1^{\prime}-0\right)$ vibronic absorption of electronic transition, and they both are in relation to the aggregation state of co-polymers (Clark et al., 2009; Hu et al., 2014; Huo et al., 2014; Fauvell et al., 2016). Herein, the relative absorption intensity of the $626 \mathrm{~nm}$ peak of the neat PTB7 film $\left(A_{1^{\prime}-0} / A_{0^{\prime}-0}\right)$ is slightly enhanced comparing with that of the PBDTTT-E film, suggesting that the fluorine substituent can influence the co-planar conformation and optical absorption of the polymer (Leclerc et al., 1993; Huo et al., 2013). Comparing with the neat film, the absorption band of the blend film is red-shift, and the absorption intensity is significantly strengthened in the wavelength range of $300-600 \mathrm{~nm}$ due to the absorption of $\mathrm{PC}_{71} \mathrm{BM}$, suggesting that $\mathrm{PC}_{71} \mathrm{BM}$ could also influence the aggregation state and optical absorption of the polymers. As for the blend active layers, PTB7: $\mathrm{PC}_{71} \mathrm{BM}$ and PBDTTT-E:PC $\mathrm{P}_{71} \mathrm{BM}$ have similar absorption characteristics in the $300-800 \mathrm{~nm}$ region, indicating that $\eta_{\mathrm{a}}$ of the two active layers is not the dominant factor to determine the photoelectric conversion performance of devices.

To further study the effect of fluorine substitution on the binding energy of polymer exciton, the PL spectra of neat polymer devices under the various bias electrical field were conducted, as shown in Figure 4. In the field of PSCs, the primary photogenerated species in most of the conjugated polymers is Frenkel-type exciton; thus, "hole-electron" binding energy is usually much higher than room temperature $k_{\mathrm{B}} \mathrm{T}$ energy $\left(25 \mathrm{meV}, k_{\mathrm{B}}\right.$, Boltzmann's constant, and $\mathrm{T}$, thermodynamic temperature) due to the weak inter-molecular interaction and low dielectric constant (Hedley et al., 2016; Wang et al., 2020). Hence, polymer exciton is hardly dissociated in the neat polymer device at room temperature. Figure 4 shows the PL spectra of neat PBDTTT-E and PTB7 devices after photoexcitation at $532 \mathrm{~nm}$ under the different biases. It can be seen that the PL intensity of neat PBDTTT-E and PTB7 devices is unchanged with the external bias range of 0 to $-2 \mathrm{~V}$, indicating this electric field has a weak influence on the dissociation of polymer excitons. Interestingly, the PL intensity of the two neat polymer devices is 

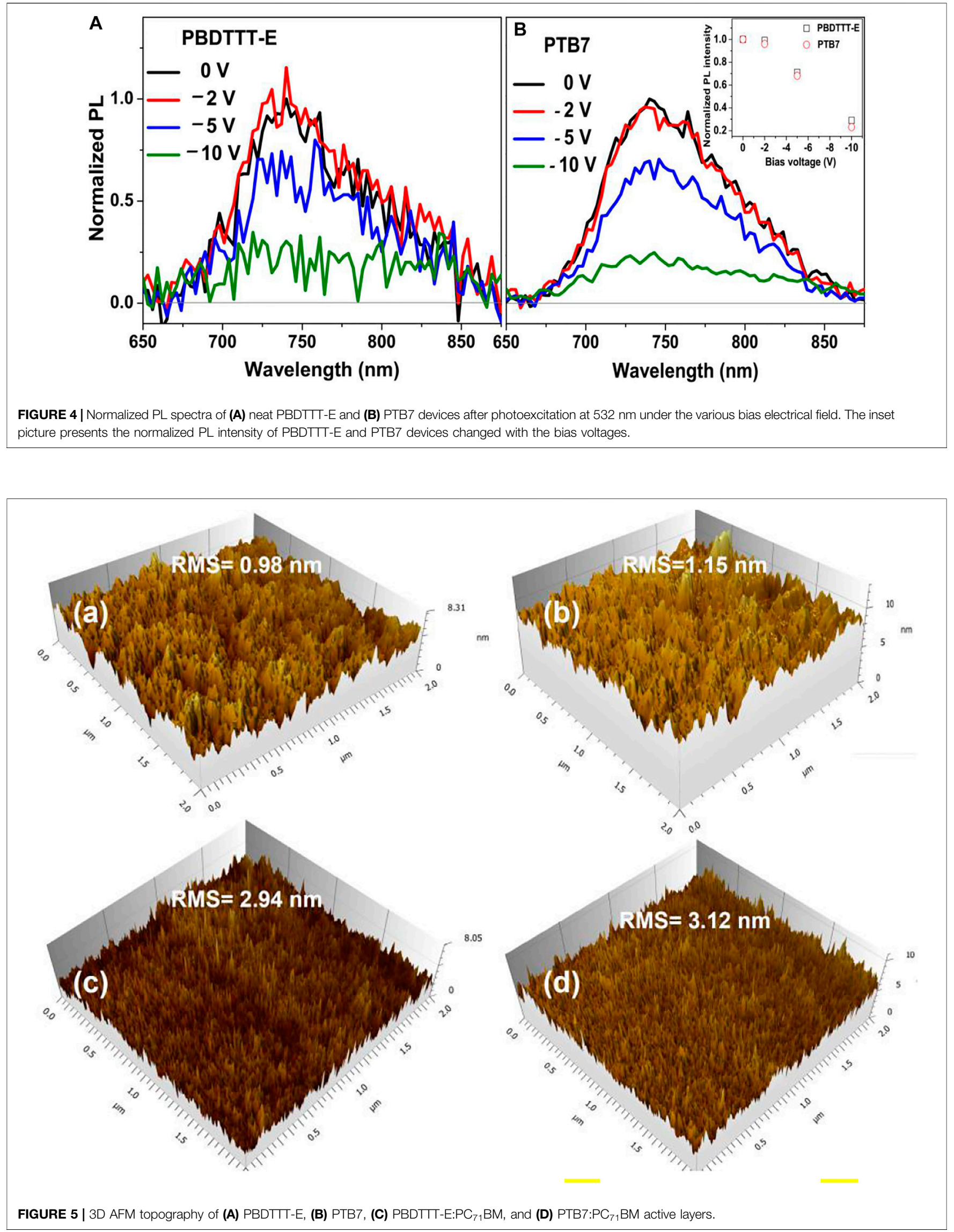


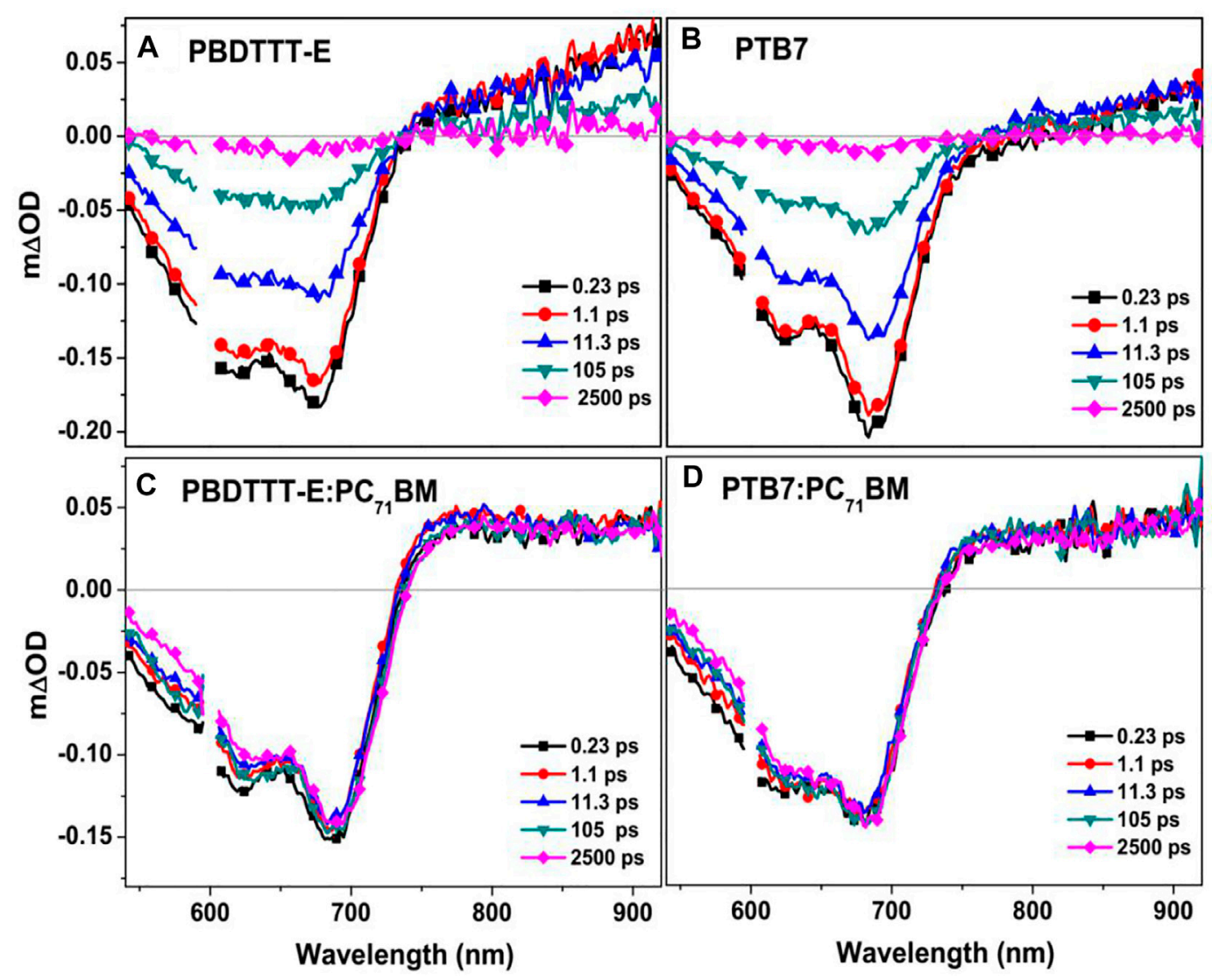

FIGURE 6 | Transient absorption spectra of (A) PBDTTT-E, (B) PTB7, (C) PBDTTT-E:PC ${ }_{71} B M$, and (D) PTB7:PC P11 $^{B}$ BM films at the different delay times recorded after photoexcitation at $600 \mathrm{~nm}$ under an excitation fluency of $2.18 \times 10^{13}$ photons $^{\bullet} \mathrm{cm}^{-2}$ pulse $^{-1}$.

gradually decreased under the high external bias $(>-2 \mathrm{~V})$. We notice that the $\sim 80 \%$ PL intensity of the two devices is quenched at a bias of $-10 \mathrm{~V}$, indicating $80 \%$ of polymer excitons are dissociated by this electric field energy. By using the electric field at $-10 \mathrm{~V}$, we estimated exciton binding energies in PBDTTT-E and PTB7 devices are 0.232 and $0.226 \mathrm{eV}$, respectively (Li H. et al., 2012; Su et al., 2021). Evidently, the neat PTB7 device has similar exciton binding energy with the PBDTTT-E device. Thus, fluorine substitution in PTB7 has a weak influence on exciton binding energy.

\section{Morphology Characterization of Active Layers}

To examine the effect of fluorine substitution on the morphology of active layers, the 3D surface features of PBDTTT-E, PTB7, PBDTTT-E:PC ${ }_{71} \mathrm{BM}$, and $\mathrm{PTB} 7: \mathrm{PC}_{71} \mathrm{BM}$ active layers were depicted by using an AFM tester, as shown in Figure 5. Figure 5A shows the surface morphology of the neat PBDTTT-E active layer. It exhibits an overall surface roughness of $0.98 \mathrm{~nm}$ (root-mean-square, RMS) in the area of $2 \times 2 \mu \mathrm{m}^{2}$. Figure 5B shows the morphology of the PTB7 active layer. Its surface roughness is measured as $1.15 \mathrm{~nm}$, which is coarser than the PBDTTT-E active layer, indicating that the fluorine-substituted TT unit facilitates the aggregation of the polymer. Figure 5C depicts the morphology of the PBDTTT$\mathrm{E}: \mathrm{PC}_{71} \mathrm{BM}$ active layer; it has a higher roughness $(2.94 \mathrm{~nm})$ than the neat PBDTTT-E film. Similarly, the surface roughness of the active layer increases from 1.15 to $3.12 \mathrm{~nm}$ when PTB7 was blended with $\mathrm{PC}_{71} \mathrm{BM}$ (Figure 5D). The increased roughness of blend films could be attributed to the formation of donor/ acceptor phase separation structures (Zhang et al., 2021). Besides, the PTB7:PC ${ }_{71} \mathrm{BM}$ layer shows a larger roughness than the PBDTTT-E:PC ${ }_{71} B M$ layer, which implies a more pronounced phase separation in the PTB7-based active layer. In PSCs, a blended active layer with appropriate phase separation is expected to facilitate carrier transport and suppress carrier recombination, leading to the efficient PSC device (Guo et al., 2009).

\section{Transient Absorption and Kinetics Characteristics of PBDTTT-E and PTB7 Films}

In the field of organic solar cells, time-resolved spectroscopy, including transient absorption and transient fluorescence, is a powerful tool for studying the charge photogeneration process (Po et al., 2010; Zhang et al., 2019). In this study, transient 

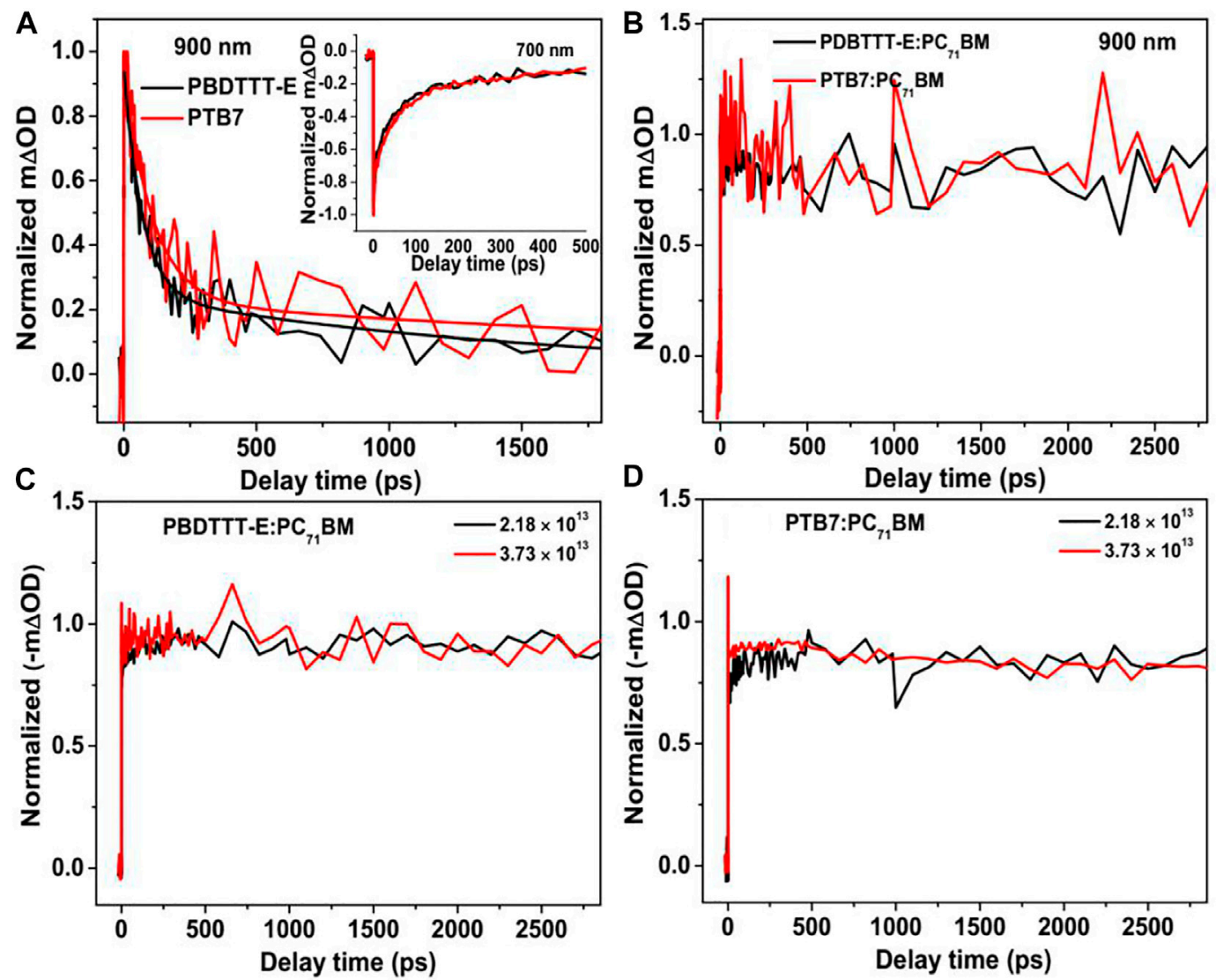

FIGURE 7 | (A) Normalized TA kinetics of the neat PBDTTT-E and PTB7 active layers at 900 and $700 \mathrm{~nm}$ and (B) normalized kinetics of the blend PBDTTT-E: $\mathrm{PC}_{71} \mathrm{BM}$ and PTB7:PC $\mathrm{PC}_{71} \mathrm{BM}$ active layers at $900 \mathrm{~nm}$; the photoexcitation energy and excitation fluency are $600 \mathrm{~nm}$ and $2.18 \times 10^{13}$ photons $^{\bullet} \mathrm{cm}^{-2} \bullet \mathrm{pulse}^{-1}$. Normalized TA bleaching kinetics $(700 \mathrm{~nm})$ of the PBDTT-E:PC $\mathrm{P}_{71} \mathrm{BM}$ (C) and PTB7:PC ${ }_{71} \mathrm{BM}$ (D) active layer after photoexcitation at $600 \mathrm{~nm}$ under the different excitation fluencies $\left(2.18 \times 10^{13}\right.$ and $3.73 \times 10^{13}$ photons $\bullet^{-2} \mathrm{~cm}^{-2}$ pulse $\left.{ }^{-1}\right)$.

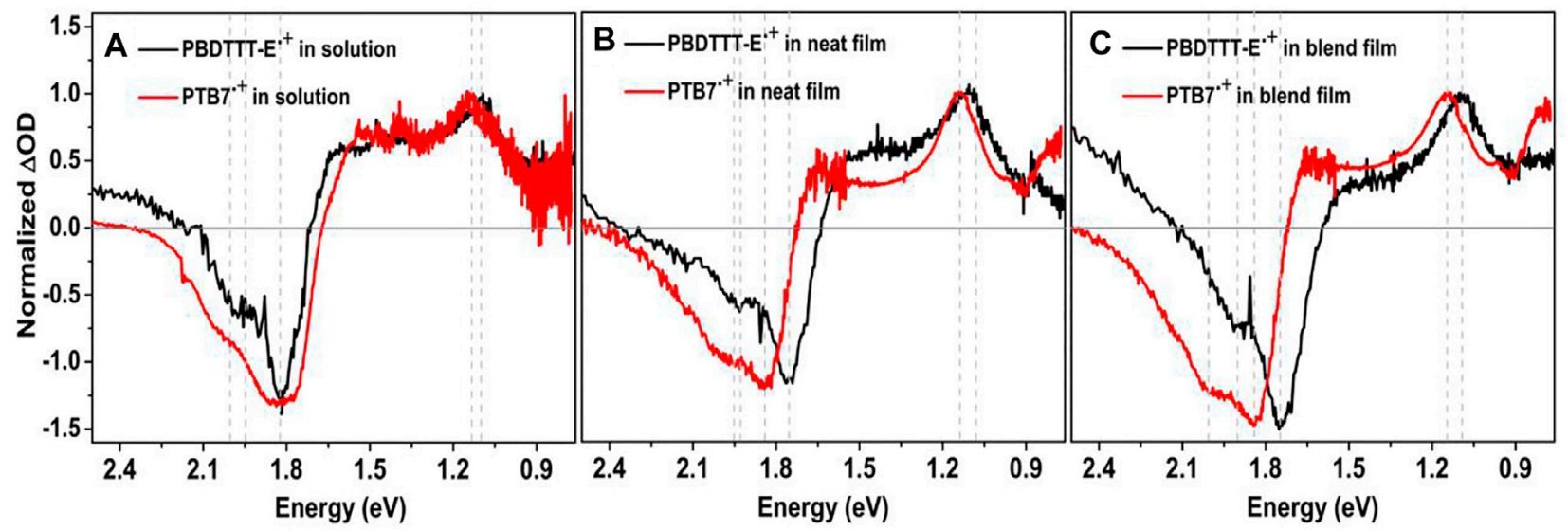

FIGURE 8 | (A-C) Spectroelectrochemical spectra of PBDTTT-E, PTB7, PBDTT-E:PC ${ }_{71} B M$, and PTB7:PC ${ }_{71} B M$ in solution and films. The applied oxidation bias was controlled at $1.5 \mathrm{~V}$ 
TABLE 2 | Transition energies (in eV) of the characteristic spectral features of polymer cations in the solution and neat and blend active layer.

\begin{tabular}{lcccccc} 
State & \multicolumn{2}{c}{ PBDTTT-E cations (peaks) } & \multicolumn{3}{c}{ PTB7 cations (peaks) } \\
\cline { 2 - 7 } & Bleaching & P2 & P1 & Bleaching & P2 & P1 \\
\hline Solution & $1.82,1.96$ & 1.09 & - & $1.82,2.02$ & 1.14 & - \\
Neat film & $1.75,1.93$ & 1.10 & - & $1.84,1.95$ & 1.14 & $\sim 0.79$ \\
Blend film & $1.75,1.90$ & 1.09 & - & $1.84,1.99$ & 1.15 & $\sim 0.79$
\end{tabular}

absorption spectroscopy was conducted to analyse the excited state and charge photogeneration characteristics from the perspective of molecular structure difference. As seen from Figures 6A,B, PBDTTT-E and PTB7 show similar spectra dynamics in the wavelength range of $550-900 \mathrm{~nm}$ in the time range of $0-2.5 \mathrm{~ns}$. Herein, the negative spectra $(550-750 \mathrm{~nm})$ are attributed to the bleaching signal. The positive signal band $(>750 \mathrm{~nm})$ is the absorption of excited states at different delay times. Figures 6C,D show the transient absorption spectra of PBDTTT-E:PC ${ }_{71} \mathrm{BM}$ and PTB7:PC ${ }_{71} \mathrm{BM}$ active layers after photoexcitation at $600 \mathrm{~nm}$ (it can excite the polymer phase in the blend film predominately at this excitation energy) under an excitation fluency of $2.18 \times$ $10^{13}$ photons $\boldsymbol{c m}^{-2} \bullet$ pulse ${ }^{-1}$. Here, the transient absorption spectra of blend active layers are significantly different from those of the neat films. First, the recovery of the ground-state bleaching spectra and the attenuation of the excited-state absorption spectra are much slower. Second, in the near infrared region, the transient absorption spectra feature of blend active layers longer than 1 ps is very similar to the steady-state absorption spectra of polymer cation (PBDTTT$\mathrm{E}^{\bullet+}$ and $\mathrm{PTB7}^{\bullet+}$, $c f$. Figure 8). Accordingly, the transient absorption spectrum of the blend films longer than 1 ps is attributed to the spectral dynamics of charge species.

To understand charge photogeneration dynamics in the active layers, the TA kinetics of neat and blend films need to be analyzed. Figure 7A shows the TA kinetics of neat PBDTTT-E and PTB7 films at $900 \mathrm{~nm}$ under the similar excitation condition. It can be seen that the kinetics can be fitted by a bi-exponential decay function, which is a predominated fast decay and a much slower decay in the ns timescale. The fast decay components of PBDTTT-E and PTB7 films are $69.6 \pm$ $5.4 \mathrm{ps}$ and $108.1 \pm 11.6 \mathrm{ps}$, respectively. The fast decay component could be attributed to the decay of excitons in neat polymer films (Su et al., 2021). The slower decay component in PBDTTT-E and PTB7 films exhibits a long lifetime of $1,598 \pm 386$ ps and 2,292 $\pm 1,140$ ps, which could be attributed to the decay of photogenerated charge (Guo et al., 2009; Guo et al., 2010). We note that the exciton lifetime of PTB7 is longer than that of PBDTTT-E. Assuming the exciton diffusion coefficients of these two neat films are comparable, a longer exciton lifetime would result in a longer exciton diffusion length, which is a critical factor for enhancing the exciton dissociation efficiency in blend films.

For the kinetics in the blend films after photoexcitation polymers predominately at $900 \mathrm{~nm}$, we note that all the kinetics decays are very slow, as shown in Figure $7 \mathbf{B}$.
Interestingly, no fast decay corresponding to the exciton dissociation of the polymer is observed in the kinetics, indicating the exciton diffusion and dissociation processes happen within the instrumental response function of $200 \mathrm{fs}$. In polymer solar cells, the size of the donor phase can determine the exciton diffusion coefficient and exciton lifetime in the blend film. The short exciton lifetime in the blend films suggests all the photogenerated excitons can arrive at the D/A interface very quick. In other words, the size of the donor phase is very small in both PBDTTT-E:PC71BM and PTB7:PC71BM active layers.

Geminate recombination and non-geminate (or bimolecular) recombination are two channels of charge loss during the process of the free charge transport in polymer solar cells. Herein, in order to clarify the charge recombination characteristics in PBDTTT-E:PC ${ }_{71} \mathrm{BM}$ and PTB7:PC ${ }_{71} \mathrm{BM}$ active layers, the $600 \mathrm{~nm}$ excitation energy with varying excitation fluencies $\left(2.18 \times 10^{13}\right.$ and $3.73 \times 10^{13}$ photons $\bullet \mathrm{cm}^{-2} \bullet$ pulse $\mathrm{e}^{-1}$ ) was used to excite the active layers, as shown in Figures 7C,D. It can be seen that both PBDTTT-E: $\mathrm{PC}_{71} \mathrm{BM}$ and PTB7:PC ${ }_{71} \mathrm{BM}$ active layers exhibit similar decay behaviors in the time range of $0-3$ ns under the low and high excitation fluencies. Hence, it can be inferred that the nongeminate recombination process is negligible at the ultrafast timescale. Based on this, we speculate that the difference of charge loss between PBDTTT-E:PC ${ }_{71} \mathrm{BM}$ and PTB7:PC ${ }_{71} \mathrm{BM}$ may originate from the bimolecular recombination process at a longer timescale ( $>3 \mathrm{~ns}$ ). Besides, the kinetics shows a slowrise process at the early timescale in Figures 7C,D. By examining TA spectra at varying delay time (Figures 6C,D), we find that the bleaching is red-shifting with delay time, which can be attributed to the transport of free carriers from high-energy states to lower-energy states. Herein, the detection wavelength of $700 \mathrm{~nm}$ is on the side of the red-shift of the bleaching peak, and thus, the kinetics at $700 \mathrm{~nm}$ would show a slow rise with the shift of the bleaching peak. Meanwhile, we also note that the rise time of the kinetics in Figures 7 C,D is comparable to the red-shift time of the bleaching peak. Therefore, the rise process in the kinetics could be attributed to that the charge transport induced the shifting of bleaching peaks in TA spectra.

\section{Spectral Characterization of the PBDTTT-E and PTB7 Radical Cations in Solution, Neat, and Blended Films}

The generation and transport of charge species are very important for the photocurrent of polymer solar cells. Polymer-positive polaron and -negative polaron could be generated by the photoexcitation process, and their transient absorption features usually have a P1 band and P2 band in the near infrared region, corresponding to the electron transition from HOMO to SOMO and SOMO to LUMO energy levels, respectively (Österbacka et al., 2000; Jiang et al., 2003). In this contribution, to analyze the effect of fluorine substitution on the charge transport in active layers, we employed an electrochemical method to produce PBDTTT-E ${ }^{\bullet+}$ and PTB7 $^{\bullet+}$ cations under the 

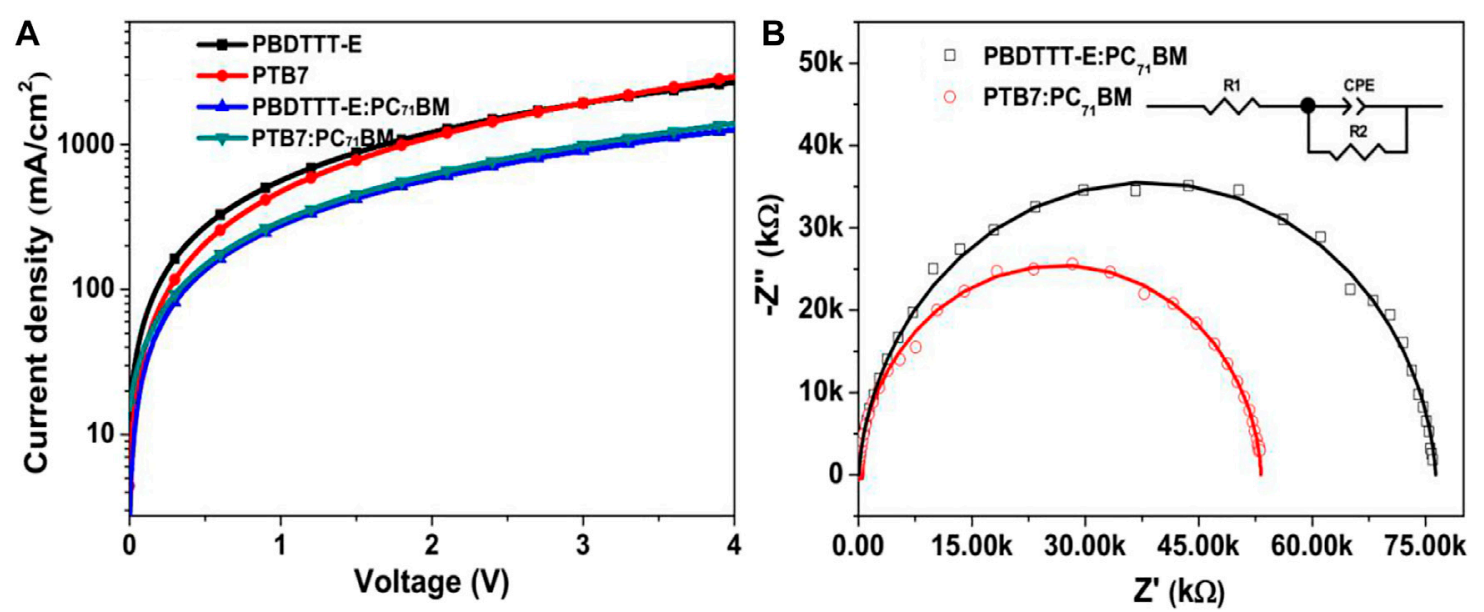

FIGURE 9 | (A) $\mathrm{J}-V$ characteristics of hole-only devices based on the configuration of ITO/MoO $/$ active layer/MoO $/ \mathrm{Ag}_{3}$ (B) EIS spectra of PBDTTT-E:PC ${ }_{71} \mathrm{BM}$ and PTB7:PC 71 BM devices.

oxidation potential. Note that the steady-state absorption spectra of the polymer cation and transient absorption spectra of polymer transient polarons should be similar under the electrochemical and photoinduction methods.

Figure 8A shows the characteristic absorption spectra of $\mathrm{PBDTTT}^{-\mathrm{E}^{\bullet+}}$ and $\mathrm{PTB}^{\bullet+}$ in solution. The negative spectra band at $1.67-2.36 \mathrm{eV}$ is designated as the electrobleaching signal that is induced by the oxidation depletion of a polymer molecule under the applied potential. Meanwhile, the positive absorption spectra appear in the near infrared region, which can be attributed to the absorption of the polymer radical cation. The positive absorption spectra and negative electrobleaching suggest a correlation between the generation process of the polymer radical cation and the oxidation depletion of the polymer ( $\mathrm{Hu}$ et al., 2021a). As for PBDTTT-E ${ }^{\bullet+}$ in solution, it shows a P2 absorption band, corresponding to the transition between SOMO to LUMO energy levels, in the region of $0.9-1.6 \mathrm{eV}$ with an absorption peak at $1.09 \mathrm{eV}$ (Table 2). However, this absorption band shows a slight blue shift for $\mathrm{PTB} 7^{\bullet+}$, and the P2 peak changes to $1.14 \mathrm{eV}$, about $0.05 \mathrm{eV}$ blue shift compared to PBDTTT-E $^{\bullet+}$. Assuming that the LUMO levels of PBDTTT$\mathrm{E}^{\bullet+}$ and $\mathrm{PTB}^{\bullet+}$ cations are similar, the blue shift of the P2 band would suggest a lower energy level of SOMO in $\mathrm{PTB}^{\bullet+}$. In neat films, we also observe a similar blue-shift characteristic for the P2 peak with $\sim 0.04 \mathrm{eV}$ after PBDTTT-E via fluorine substitution.

Furthermore, we analyzed the difference of PBDTTT-E ${ }^{\bullet+}$ and $\mathrm{PTB}^{\circ}{ }^{\circ}$ in blend active layers, as seen from Figure $\mathbf{8 C}$ and Table 2. In the blend films, the electrobleaching spectrum and $\mathrm{P} 2$ peak of $\mathrm{PTB}^{\bullet+}$ are both blue shift compared with PBDTTT-

TABLE 3 | Electrical parameter values in blend devices.

\begin{tabular}{lcccc}
\hline Devices & $\mathbf{R 1}(\boldsymbol{\Omega})$ & $\mathbf{R 2}(\boldsymbol{\Omega})$ & CPE-T (F) & CPE-P \\
\hline PBDTाT-E:PC 71 BM & 38.57 & 76,286 & $2.48 \times 10^{-9}$ & 0.9468 \\
PTB7:PC ${ }_{71} \mathrm{BM}$ & 23.36 & 53,200 & $2.75 \times 10^{-9}$ & 0.9719
\end{tabular}

$\mathrm{E}^{\bullet+}(1.75-1.84 \mathrm{eV}, 1.90-1.99 \mathrm{eV}$, and $1.09-1.15 \mathrm{eV})$. The blueshift feature in the blend active layer is even more pronounced than that in the solution and neat polymer films. For PBDTTT$\mathrm{E}^{\bullet+}$, we find the $\mathrm{P} 2$ peak energy in the neat film is $\sim 0.01 \mathrm{eV}$ higher than that in the blend film, while the $\mathrm{P} 2$ peak energy in the neat film is $\sim 0.01 \mathrm{eV}$ lower than that in the blend film for $\mathrm{PTB}^{\bullet+}$. As mentioned above, a higher P2 energy would suggest a lower SOMO level. Here, we deduce that the SOMO level energy of $\mathrm{PTB}^{\circ+}$ in the blend film is lower than that in the neat PTB7 film. On the contrary, the SOMO level energy of PBDTTT-E ${ }^{\bullet+}$ in the blend film is higher than that in the neat film. In polymer solar cells, there are two situations for the donor phase in the blend film: one is the polymers at the D/A interface, and the other is the polymers in the center of the donor phase which is similar to that in the neat polymer film. Considering these two situations in blend films, we deduce the SOMO energy level of PTB7 ${ }^{\bullet+}$ in the center of the donor phase is higher than that at the interface. This energy level distribution could facilitate the hole transport from the interface into the center of the donor phase and suppress the charge recombination processes. On the contrary, for the PBDTTT-E blend film, the energy level distribution is not conducive to the transport of holes at the interface.

\section{Electrical Characteristics of Devices}

To further quantitatively analyze the charge transport property in PSCs, SCLC measurement was carried out to estimate the charge carrier mobility according to the literature (Zhang et al., 2014, and the $J-V$ curves are shown in Figure 9A. Hole mobility $\left(\mu_{\mathrm{h}}\right)$ can be calculated using the Mott-Gurney law follows:

$$
J=\frac{9}{8} \varepsilon_{0} \varepsilon_{\mathrm{r}} \mu_{\mathrm{h}} \frac{V^{2}}{d^{3}} .
$$

Here, $\varepsilon_{\mathrm{r}}$ is the relative permittivity of the conjugate polymer $\left(\varepsilon_{\mathrm{r}}=3\right), \varepsilon_{0}$ is the vacuum dielectric constant $(8.85 \times$ $\left.10^{-12} \mathrm{~F} \mathrm{~m}^{-1}\right), V$ is the applied bias, and $d$ is the thickness of the active layer. We obtained the thicknesses of neat films and 
blend films as $\sim 90$ and $\sim 110 \mathrm{~nm}$. By calculation, the hole mobilities are $4.1 \times 10^{-3}, 4.5 \times 10^{-3}, 3.1 \times 10^{-4}$, and $3.4 \times$ $10^{-4} \mathrm{~cm}^{2} \mathrm{~V}^{-1} \mathrm{~s}^{-1}$ in PBDTTT-E, PTB7, PBDTTT-E:PC ${ }_{71} \mathrm{BM}$, and PTB7:PC ${ }_{71} \mathrm{BM}$ devices, respectively. Apparently, PTB7based devices have higher hole mobilities than PBDTTT-Ebased devices, suggesting that fluorine substitution has an important effect on transport efficiency $\left(\eta_{c t}\right)$. To further analyse charge carrier recombination characteristics in blend devices, EIS measurements of devices were conducted under the dark condition, as shown in Figure 9B. The results of the two blend devices were analysed with an equivalent circuit (inset picture of Figure 9B). Herein, R1 contains the electrodes, the active layer/metal electrode interface, and the active layer. The constant-phase element (CPE) is usually used to simulate the dielectric effect of the device for better fitting. $\mathrm{R} 2$ is often considered as a charge-transfer (or recombination) resistor. Thus, it reflects the charge carrier recombination. In this work, all EIS spectra were fitted by a simulation function installed in the measurement software (Zview2), and the fitting parameters are shown in Table 3. R1 values are 38.57 and 23.36 $\Omega$ in PBDTTT-E:PC ${ }_{71} \mathrm{BM}$ and PTB7:PC ${ }_{71} \mathrm{BM}$ devices, respectively, indicating that the $\mathrm{PTB} 7: \mathrm{PC}_{71} \mathrm{BM}$ device has a small photocurrent loss at the active layer or interface. Besides, the PTB7:PC ${ }_{71} \mathrm{BM}$ device shows a smaller R2 value $(53,200 \Omega)$ than the PBDTTT-E:PC ${ }_{71} \mathrm{BM}$ device $(76,286 \Omega)$. Hence, it implies that the PTB7-based device is more favorable for suppressing charge recombination during the charge transport process. CPE values also indicate a better charge transport channel in the $\mathrm{PTB} 7: \mathrm{PC}_{71} \mathrm{BM}$ device.

\section{CONCLUSION}

In summary, we have spectroscopically characterized the exciton and polaron species in the neat PBDTTT-E (PTB7) and the blend PBDTTT-E (PTB7):PC71BM active layers and investigated their charge transport and charge recombination behaviors. PTB7 and PBDTTT-E showed a fluorine atom substitution difference on the TT unit, leading to the different device performance. Our results showed that the influence of fluorine substitution on the exciton binding energy of the polymer and the carrier recombination dynamics in the ultrafast timescale is insignificant. Besides,

\section{REFERENCES}

Arias, A. C., MacKenzie, J. D., McCulloch, I., Rivnay, J., and Salleo, A. (2010). Materials and Applications for Large Area Electronics: Solution-Based Approaches. Chem. Rev. 110, 3-24. doi:10.1021/cr900150b

Bhatta, R. S., and Tsige, M. (2014). Chain Length and Torsional Dependence of Exciton Binding Energies in P3HT and PTB7 Conjugated Polymers: A FirstPrinciples Study. Polymer 55, 2667-2672. doi:10.1016/j.polymer.2014.04.022

Chao, P., Mu, Z., Wang, H., Mo, D., Chen, H., Meng, H., et al. (2018). Chlorination of Side Chains: A Strategy for Achieving a High Open Circuit Voltage over $1.0 \mathrm{~V}$ in Benzo[1,2-B:4,5-B'] dithiophene-Based Non-fullerene Solar Cells. ACS Appl. Energ. Mater. 1, 2365-2372. doi:10.1021/acsaem.8b00506 we found that the fluorine substitution in the conjugated polymer could enhance the exciton lifetime in the neat polymer film, and it also could increase the mobility of photogenerated charge. Moreover, we found that the SOMO energy level distribution of the donor in PTB7:PC71BM solar cells could facilitate hole transport from the D/A interface to the center of the donor phase, showing a better advantage than the PBDTTT-E:PC71BM solar cell. Longer exciton lifetime and appropriate energy level arrangement played critical roles for an efficient PTB7:PC71BM device.

\section{DATA AVAILABILITY STATEMENT}

The original contributions presented in the study are included in the article/supplementary material, further inquiries can be directed to the corresponding authors.

\section{AUTHOR CONTRIBUTIONS}

$\mathrm{RH}$ and WZ designed this work. RH carried out the $J-V$, EIS, and SEC experiments. YL provided AFM and absorption data. JP provided PL data. JJ and MQ provided assistance for data analysis. XH provided TA data. $\mathrm{M}-\mathrm{MH}$ provided contribution suggestions of the manuscript. $\mathrm{RH}$ wrote the manuscript. WZ helped to revise the manuscript. All authors contributed to the manuscript and approved the final version.

\section{FUNDING}

This work was funded by the National Natural Science Foundation of China (21903017), Major Cultivation Project of Chongqing University of Arts and Sciences (P2020CL01), the Science and Technology Research Program of the Chongqing Municipal Education Commission (KJQN201901319 and KJQN202001323), General program of Chongqing Natural Science Foundation (cstc2019jcyj-msxmX0874, cstc2019jcyjmsxmX0875, and cstc2019jcyj-msxmX0411), Guangzhou Science and Technology Planning Project (202102010443), and Young Talents Program of Guangzhou University (Grant No. RQ2020080).

Chen, F. X., Xu, J. Q., Liu, Z. X., Chen, M., Xia, R., Yang, Y., et al. (2018). NearInfrared Electron Acceptors with Fluorinated Regioisomeric Backbone for Highly Efficient Polymer Solar Cells. Adv. Mater. 30, 1803769. doi:10.1002/ adma.201803769

Chen, H., Hu, Z., Wang, H., Liu, L., Chao, P., Qu, J., et al. (2018). A Chlorinated $\pi-$ Conjugated Polymer Donor for Efficient Organic Solar Cells. Joule 2, 1623-1634. doi:10.1016/j.joule.2018.05.010

Chen, L., Wu, M., Shao, G., Hu, J., He, G., Bu, T., et al. (2018). A Helical Perylene Diimide-Based Acceptor for Non-fullerene Organic Solar Cells: Synthesis, Morphology and Exciton Dynamics. R. Soc. Open Sci. 5, 172041. doi:10. 1098/rsos.172041

Clark, J., Chang, J.-F., Spano, F. C., Friend, R. H., and Silva, C. (2009). Determining Exciton Bandwidth and Film Microstructure in Polythiophene Films Using 
Linear Absorption Spectroscopy. Appl. Phys. Lett. 94, 163306. doi:10.1063/1. 3110904

Clarke, T. M., and Durrant, J. R. (2010). Charge Photogeneration in Organic Solar Cells. Chem. Rev. 110, 6736-6767. doi:10.1021/cr900271s

Dang, M. T., Hirsch, L., Wantz, G., and Wuest, J. D. (2013). Controlling the Morphology and Performance of Bulk Heterojunctions in Solar Cells. Lessons Learned from the Benchmark Poly(3-Hexylthiophene):[6,6]-Phenyl-C61-Butyric Acid Methyl Ester System. Chem. Rev. 113, 3734-3765. doi:10.1021/cr300005u

Dehnen, S., Schafer, L. L., Lectka, T., and Togni, A. (2021). Fluorine: A Very Special Element and its Very Special Impacts on Chemistry. Inorg. Chem. 60, 17419-17425. doi:10.1021/acs.inorgchem.1c03509

Dennler, G., Scharber, M. C., Ameri, T., Denk, P., Forberich, K., Waldauf, C., et al. (2008). Design Rules for Donors in Bulk-Heterojunction Tandem Solar CellsTowards 15\% Energy-Conversion Efficiency. Adv. Mater. 20, 579-583. doi:10. 1002/adma.200702337

Dunitz, J. D., and Taylor, R. (1997). Organic Fluorine Hardly Ever Accepts Hydrogen Bonds. Chem. Eur. J. 3, 89-98. doi:10.1002/chem.19970030115

Fauvell, T. J., Zheng, T., Jackson, N. E., Ratner, M. A., Yu, L., and Chen, L. X. (2016). Photophysical and Morphological Implications of Single-Strand Conjugated Polymer Folding in Solution. Chem. Mater. 28, 2814-2822. doi:10.1021/acs.chemmater.6b00734

Guo, J., Ohkita, H., Benten, H., and Ito, S. (2009). Near-IR Femtosecond Transient Absorption Spectroscopy of Ultrafast Polaron and Triplet Exciton Formation in Polythiophene Films with Different Regioregularities. J. Am. Chem. Soc. 131, 16869-16880. doi:10.1021/ja906621a

Guo, J., Ohkita, H., Yokoya, S., Benten, H., and Ito, S. (2010). Bimodal Polarons and Hole Transport in Poly(3-hexylthiophene):Fullerene Blend Films. J. Am. Chem. Soc. 132, 9631-9637. doi:10.1021/ja9108787

He, X., Mukherjee, S., Watkins, S., Chen, M., Qin, T., Thomsen, L., et al. (2014). Influence of Fluorination and Molecular Weight on the Morphology and Performance of PTB7:PC71BM Solar Cells. J. Phys. Chem. C 118, 9918-9929. doi:10.1021/jp501222w

Hedley, G. J., Ruseckas, A., and Samuel, I. D. W. (2016). Light Harvesting for Organic Photovoltaics. Chem. Rev. 117, 796-837. doi:10.1021/acs.chemrev. $6 \mathrm{~b} 00215$

Hu, R., Liu, Y., Cheng, J., Chen, Y., Zhang, W., and Liu, H. (2018). Effect of [6,6]phenyl C61-Butyric Acid Methyl Ester Phase on the Charge Generation of Poly(3-Hexylthiophene)-Based Polymer Solar Cells. J. Power Sourc. 390, 87-92. doi:10.1016/j.jpowsour.2018.04.041

Hu, R., Zhang, L., Peng, J., and Zhang, W. (2021a). Comparative Study of Charge Characteristics in PCPDTBT:fullerenes Solar Cells. Chem. Phys. 540, 111004. doi:10.1016/j.chemphys.2020.111004

Hu, R., Zhang, W., Wang, P., Qin, Y., Liang, R., Fu, L.-M., et al. (2014). Characterization and Distribution of Poly(3-Hexylthiophene) Phases in an Annealed Blend Film. ChemPhysChem 15, 935-941. doi:10.1002/cphc. 201301147

Hu, R., Zhang, W., Xiao, Z., ZhangSu, J. X., Su, X., Wang, G., et al. (2021b). Charge Photogeneration and Recombination in Ternary Polymer Solar Cells Based on Compatible Acceptors. J. Mater. Sci. 56, 14181-14195. doi:10.1007/s10853-02106232-2

Huo, M.-M., Hu, R., Xing, Y.-D., Liu, Y.-C., Ai, X.-C., Zhang, J.-P., et al. (2014). Impacts of Side Chain and Excess Energy on the Charge Photogeneration Dynamics of Low-Bandgap Copolymer-Fullerene Blends. J. Chem. Phys. 140, 084903. doi:10.1063/1.4866177

Huo, M.-M., Liang, R., Xing, Y.-D., Hu, R., Zhao, N.-J., Zhang, W., et al. (2013). Side-chain Effects on the Solution-phase Conformations and Charge Photogeneration Dynamics of Low-Bandgap Copolymers. J. Chem. Phys. 139, 124904. doi:10.1063/1.4821751

Jackson, N. E., Savoie, B. M., Kohlstedt, K. L., Olvera de la Cruz, M., Schatz, G. C., Chen, L. X., et al. (2013). Controlling Conformations of Conjugated Polymers and Small Molecules: The Role of Nonbonding Interactions. J. Am. Chem. Soc. 135, 10475-10483. doi:10.1021/ja403667s

Jia, X. e., Liu, G., Chen, S., Li, Z., Wang, Z., Yin, Q., et al. (2019). Backbone Fluorination of Polythiophenes Improves Device Performance of Non-fullerene Polymer Solar Cells. ACS Appl. Energ. Mater. 2, 7572-7583. doi:10.1021/acsaem.9b01532

Jiang, X. M., Österbacka, R., An, C. P., and Vardeny, Z. V. (2003). Photoexcitations in Regio-Regular and Regio-Random Polythiophend Films. Synth. Met. 137, 1465-1468. doi:10.1016/S0379-6779(00)00487-2
Kim, J. Y., Lee, K., Coates, N. E., Moses, D., Nguyen, T.-Q., Dante, M., et al. (2007). Efficient Tandem Polymer Solar Cells Fabricated by All-Solution Processing. Science 317, 222-225. doi:10.1126/science.1141711

Kniepert, J., Lange, I., Heidbrink, J., Kurpiers, J., Brenner, T. J. K., Koster, L. J. A., et al. (2015). Effect of Solvent Additive on Generation, Recombination, and Extraction in PTB7:PCBM Solar Cells: A Conclusive Experimental and Numerical Simulation Study. J. Phys. Chem. C 119, 8310-8320. doi:10.1021/ jp512721e

Leclerc, M., Roux, C., and Bergeron, J.-Y. (1993). Structural Effects on the Thermochromic Properties of Polythiophene Derivatives. Synth. Met. 55, 287-292. doi:10.1016/0379-6779(93)90947-U

Li, C, C., Zhou, J., Song, J., Xu, J., Zhang, H., Zhang, X., et al. (2021). Non-fullerene Acceptors with Branched Side Chains and Improved Molecular Packing to Exceed 18\% Efficiency in Organic Solar Cells. Nat. Energ. 6, 605-613. doi:10. 1038/s41560-021-00820-x

Li, H, H., Chen, Z., Tang, H., Xu, W., Li, J., Zhao, X., et al. (2012). An Aqueous Soaking Treatment for Efficient Polymer Solar Cells. RSC Adv. 2, 10231-10237. doi:10.1039/c2ra21193a

Liang, Y., Xu, Z., Xia, J., Tsai, S. T., Wu, Y., Li, G., et al. (2010). For the Bright Future-Bulk Heterojunction Polymer Solar Cells with Power Conversion Efficiency of 7.4\%. Adv. Mater. 22, E135-E138. doi:10.1002/adma.200903528

Lin, Y., Lin, Y., Nugraha, M. I., Firdaus, Y., Scaccabarozzi, A. D., Aniés, F., et al. (2020). A Simple N-Dopant Derived from Diquat Boosts the Efficiency of Organic Solar Cells to 18.3. ACS Energ. Lett 5, 3663-3671. doi:10.1021/ acsenergylett.0c01949

Liu, L., Zhang, H., Xiao, B., Liu, Y., Xu, B., Wang, C., et al. (2021). Effects of BTA2 as the Third Component on the Charge Carrier Generation and Recombination Behavior of PTB7:PC71BM Photovoltaic System. Front. Chem. Sci. Eng. 15, 127-137. doi:10.1007/s11705-020-1936-7

Liu, Q., Jiang, Y., Jin, K., Qin, J., Xu, J., Li, W., et al. (2020). 18\% Effificiency Organic Solar Cells. Sci. Bull. 65, 272-275. doi:10.1016/j.scib.2020.01.001

Lu, L., and Yu, L. (2014). Understanding Low Bandgap Polymer PTB7 and Optimizing Polymer Solar Cells Based on it. Adv. Mater. 26, 4413-4430. doi:10.1002/adma.201400384

Lu, S., Sun, Y., Ren, K., Liu, K., Wang, Z., and Qu, S. (2018). Recent Development in ITO-free Flexible Polymer Solar Cells. Polymers 10, 5. doi:10.3390/ polym 10010005

Matheson, A. B., Ruseckas, A., Pearson, S. J., and Samuel, I. D. W. (2019). Hole Delocalization as a Driving Force for Charge Pair Dissociation in Organic Photovoltaics. Mater. Horiz. 6, 1050-1056. doi:10.1039/c8mh01204k

Moritomo, Y., Yonezawa, K., and Yasuda, T. (2016). Carrier Formation Dynamics in Prototypical Organic Solar Cells as Investigated by Transient Absorption Spectroscopy. Int. J. Photoenergy 2016, 1-17. doi:10.1155/2016/9105460

Österbacka, R., An, C. P., Jiang, X. M., and Vardeny, Z. V. (2000). Twodimensional Electronic Excitations in Self-Assembled Conjugated Polymer Nanocrystals. Science 287, 839-842. doi:10.1126/science.287.5454.839

Po, R., Maggini, M., and Camaioni, N. (2010). Polymer Solar Cells: Recent Approaches and Achievements. J. Phys. Chem. C 114, 695-706. doi:10.1021/ jp9061362

Shang, Q., Yu, J., Hu, R., Liu, Z., Cheng, J., Li, Y., et al. (2020). Enhanced Charge Transport in Conventional Polymer Solar Cells with a Perovskite-type LaNiO3 Layer. ACS Appl. Mater. Inter. 12, 13051-13060. doi:10.1021/acsami.9b22049

Sharma, R., Gupta, V., Lee, H., Borse, K., Datt, R., Sharma, C., et al. (2018). Charge Carrier Dynamics in PffBT4T-2OD: PCBM Organic Solar Cells. Org. Electro. 62, 441-447. doi:10.1016/j.orgel.2018.08.018

Sharma, R., Lee, H., Gupta, V., Kim, H., Kumar, M., Sharma, C., et al. (2016). Photo-physics of PTB7, PCBM and ICBA Based Ternary Solar Cells. Org. Electro. 34, 111-117. doi:10.1016/j.orgel.2016.04.022

Su, X., Hu, R., Wen, G., Zou, X., Qing, M., Peng, J., et al. (2021). Understanding of Photophysical Processes in DIO Additive-Treated PTB7:PC71BM Solar Cells. Crystals 11, 1139. doi:10.3390/cryst11091139

Sun, S., Salim, T., Mathews, N., Duchamp, M., Boothroyd, C., Xing, G., et al. (2014). The Origin of High Efficiency in Low-Temperature Solution-Processable Bilayer Organometal Halide Hybrid Solar Cells. Energy Environ. Sci. 7, 399-407. doi:10.1039/C3EE43161D

Wang, J., Zheng, Z., Zu, Y., Wang, Y., Liu, X., Zhang, S., et al. (2021). A Tandem Organic Photovoltaic Cell with 19.6\% Efficiency Enabled by Light Distribution Control. Adv. Mater. 33, 2102787. doi:10.1002/adma.202102787 
Wang, R., Zhang, C., Li, Q., Zhang, Z., Wang, X., and Xiao, M. (2020). Charge Separation from an Intra-moiety Intermediate State in the High-Performance PM6:Y6 Organic Photovoltaic Blend. J. Am. Chem. Soc. 142, 12751-12759. doi:10.1021/jacs.0c04890

Wu, M., Yi, J.-P., Chen, L., He, G., Chen, F., Sfeir, M. Y., et al. (2018). Novel StarShaped Helical Perylene Diimide Electron Acceptors for Efficient Additive-free Nonfullerene Organic Solar Cells. ACS Appl. Mater. Inter. 10, 27894-27901. doi:10.1021/acsami.8b06126

Zhang, M., Guo, X., Zhang, S., and Hou, J. (2014). Synergistic Effect of Fluorination on Molecular Energy Level Modulation in Highly Efficient Photovoltaic Polymers. Adv. Mater. 26, 1118-1123. doi:10.1002/adma.201304427

Zhang, Q., Kelly, M. A., Bauer, N., and You, W. (2017). The Curious Case of Fluorination of Conjugated Polymers for Solar Cells. Acc. Chem. Res. 50, 2401-2409. doi:10.1021/acs.accounts.7b00326

Zhang, T., An, C. B., Lv, Q., Qin, J., Cui, Y., Zheng, Z., et al. (2021). Optimizing Polymer Aggregation and Blend Morphology for Boosting the Photovoltaic Performance of Polymer Solar Cells via a Random Terpolymerization Strategy. J. Energ. Chem. 59, 30-37. doi:10.1016/j.jechem.2020.11.021

Zhang, W., Hu, R., Li, D., Huo, M.-M., Ai, X.-C., and Zhang, J.-P. (2012). Primary Dynamics of Exciton and Charge Photogeneration in Solvent Vapor Annealed P3HT/PCBM Films. J. Phys. Chem. C 116, 4298-4310. doi: $10.1021 /$ jp $211653 x$
Zhang, W., Hu, R., Zeng, X., Su, X., Chen, Z., Zou, X., et al. (2019). Effect of PostThermal Annealing on the Performance and Charge Photogeneration Dynamics of PffBT4T-2OD/PC71BM Solar Cells. Polymers 11, 408. doi:10. 3390/polym11030408

Conflict of Interest: The authors declare that the research was conducted in the absence of any commercial or financial relationships that could be construed as a potential conflict of interest.

Publisher's Note: All claims expressed in this article are solely those of the authors and do not necessarily represent those of their affiliated organizations, or those of the publisher, the editors, and the reviewers. Any product that may be evaluated in this article, or claim that may be made by its manufacturer, is not guaranteed or endorsed by the publisher.

Copyright (C) $2022 \mathrm{Hu}$, Liu, Peng, Jiang, Qing, He, Huo and Zhang. This is an openaccess article distributed under the terms of the Creative Commons Attribution License (CC BY). The use, distribution or reproduction in other forums is permitted, provided the original author(s) and the copyright owner(s) are credited and that the original publication in this journal is cited, in accordance with accepted academic practice. No use, distribution or reproduction is permitted which does not comply with these terms. 